\title{
District-level strategies to control the HIV epidemic in Zimbabwe: a practical example of precision public health
}

\author{
Richard Makurumidze ${ }^{1,2,4^{*}} \mathbb{D}$, Tom Decroo ${ }^{2,3}$, Lutgarde Lynen², Zororo Kudzaishe Chinwadzimba ${ }^{5}$,
} Wim Van Damme ${ }^{2,4}$, James Hakim ${ }^{1}$ and Simbarashe Rusakaniko ${ }^{1}$

\begin{abstract}
Objective: We conducted a descriptive cross-sectional study using survey and programme data to assess districtlevel performance along the HIV care cascade (HIV testing target achievement, linkage to ART and ART coverage) in order to formulate district-specific recommendations, taking into consideration prevalence and yield of testing.

Results: Data from 60 districts were analysed. Forty-eight districts (80.0\%) surpassed 90\% of their 2018 HIV testing targets. Linkage to ART was less than $90 \%$ in 40 districts (83.3\%). Thirty districts (50.0\%) had ART coverage above $90 \%$. Of the 30 districts with suboptimal (<90\%) ART coverage, 18 districts had achieved high HIV testing target but with suboptimal linkage to ART, 6 had achieved high HIV testing targets and high linkage to ART, 4 had both suboptimal HIV testing target achievement and linkage to ART and 2 had suboptimal HIV testing target achievement and high linkage to ART. Priority should be given to districts with suboptimal ART coverage. Remediation strategies should be tailored to address the poorly performing stage of the cascade in each of the districts.
\end{abstract}

Keywords: HIV testing, Linkage to care, ART coverage, 90-90-90 targets, Implementation, Precision public health, Zimbabwe

\section{Introduction}

In 2019, Zimbabwe had about 1.2 million [95\% confidence interval (CI): 1.1-1.4 million] people living with HIV (PLHIV) [1]. The number of new HIV infections decreased by $35.3 \%$, from 62000 [95\% CI $45000-83$ 000] to 38000 [95\% CI 28 000-51 000] between 2010 and 2018. HIV-related deaths also decreased by $42.6 \%$, from 54,000 [95\% CI 43,000-68,000] to 22,000 [95\% CI 17,000-27 000] during the same period [1]. The Zimbabwe Population-Based HIV Impact Assessment (ZIMPHIA) survey, conducted in 2015-2016 to assess progress towards the UNAIDS 90-90-90 targets [2], showed that $74.2 \%$ of all PLHIV reported knowing their HIV status,

*Correspondence: rmakurumidze@ext.itg.be

${ }^{1}$ College of Health Sciences, University of Zimbabwe, Harare, Zimbabwe Full list of author information is available at the end of the article of whom $86.8 \%$ were on antiretroviral therapy (ART) and $86.5 \%$ of those on ART were virally suppressed [3].

Most countries show national data, without evidence on whether this mirrors the data at sub-national levels. Hence, most national programmes, including those in Zimbabwe, do not provide recommendations adapted for district-level indicators. At the same time, donors call for targeted and cost-effective strategies, due to dwindling funds $[4,5]$. Advances in information technology provide an opportunity for data-driven health interventions. In our study, we combined mapping data on HIV prevalence [6] with data from the Zimbabwe National ART Program 2018. We studied the district-level performance along the HIV care cascade (HIV testing target achievement, linkage to ART and ART coverage) and formulated districtlevel recommendations considering HIV prevalence and HIV testing yield. 


\section{Main text Methods}

We conducted a descriptive cross-sectional study and retrieved the district-level HIV prevalence from the mapping study [6].

For each district, the number of people tested and the number tested positive and initiated on ART in 2018, and the total number of clients on ART at the end of 2018 were obtained from the Ministry of Health and Child Care (MoHCC), District Health Information System 2 (DHIS 2) [7]. Permission was obtained from the relevant authorities.

To estimate the district-level HIV testing achievement in 2018, we first calculated the district-level targets. We calculated the percentage of PLHIV in every district by dividing the estimated number of PLHIV in a district with the estimated total number of PLHIV in the country in 2018. We then use this percentage to distribute the overall national HIV testing target for 2018 to the districts $[8,9]$. Second, we calculated the testing coverage by dividing the number of tests conducted with the district target (number of tests proposed by each district) [10]. The HIV testing yield was calculated by dividing the number of positive tests with the number of tests conducted per district.

Linkage to ART was estimated by dividing the number of patients that were started on ART in 2018 with the number of positive tests in the same year (with the assumption that under the World Health Organization's HIV "Treat All" recommendations, all those tested positive had been put on ART [11]). The ART coverage was estimated by dividing the number of patients reported as active on ART at the end of 2018 in a district with the total number of PLHIV in that district.

HIV testing target achievement, linkage to ART and ART coverage were categorised into low $(<70 \%)$, medium (70-90\%) and high (>90\%) and the districtlevel categorisation was visualized on maps using geographic information systems (GIS).

We also described district-level performance along the HIV cascade for those districts with suboptimal $(<90 \%)$ ART coverage. These were grouped as follows: 1. Suboptimal HIV testing target achievement/suboptimal linkage to ART, 2. Suboptimal HIV testing target achievement/high linkage to ART, 3. High HIV testing target achievement/suboptimal linkage to ART and 4 . High HIV testing target achievement/high linkage to ART.

\section{Results}

We included all the districts of Zimbabwe in the analysis. District-level categorization of HIV prevalence, HIV testing target achievement, linkage to ART and ART coverage are shown in Fig. 1.

The highest prevalence was in Bubi District (21.5\%) followed by Bulilima District (20.8\%) and Tsholotsho District (20.7\%). Forty-eight districts (80.0\%) surpassed $90 \%$ of their 2018 HIV testing target. Only three reported a low $(<70 \%)$ testing coverage: Insiza (69.2\%), Chikomba (62.7\%) and Umzingwane (62.5\%). A total of 29 districts (48.3\%) had an HIV testing yield between 5.0 and 7.5\% (Additional file 1: Figure S1). Linkage to ART was less than $90 \%$ in 40 districts $(83.3 \%)$.

Thirty districts (50.0\%) had high ART coverage (>90\%). Of the 30 districts with suboptimal coverage, 24 districts (40.0\%) had medium coverage (70-90\%), while the ART coverage was low $(<70 \%)$ in 6 districts $(10.0 \%)$ : Gokwe North (39.4\%), Gokwe South (44.4\%), Umguza (49.7\%), Centenary (61.0\%), Uzumba-Maramba-Pfungwe (63.0\%) and Binga (68.0\%).

Table 1 shows the district-level performance along the HIV cascade among 30 districts with suboptimal ART coverage $(<90 \%)$. Of the 30 districts, 4 had both suboptimal HIV testing target achievement and linkage to ART, 18 had high HIV testing target achievement but suboptimal linkage to ART, 6 had high HIV testing target achievement and high linkage to ART and 2 had suboptimal HIV testing coverage but high linkage to ART.

\section{Discussion}

In Zimbabwe, half of the districts had high (>90\%) ART coverage, and thus had achieved the second target of the UNAIDS 90-90-90 targets [2]. However, substantial within-country variations in terms of HIV prevalence, HIV testing coverage, HIV testing yield, linkage to ART and ART coverage were observed. We have proposed four categories of districts according to gaps along the HIV cascade, for which district-specific recommendations can be formulated.

\section{Suboptimal HIV testing target achievement and suboptimal linkage to ART}

In the four districts with both suboptimal HIV testing achievement and linkage to ART, both the HIV prevalence and the HIV testing yield were above average, highlighting an important unmet need for HIV testing services. Therefore, HIV testing services should become more widely available. It has been seen that widespread door-to-door HIV testing substantially increases the acceptance of HIV testing and should be considered as a priority [12]. In addition, strategies linking those who tested positive to ART should be strengthened (elaborated below). 

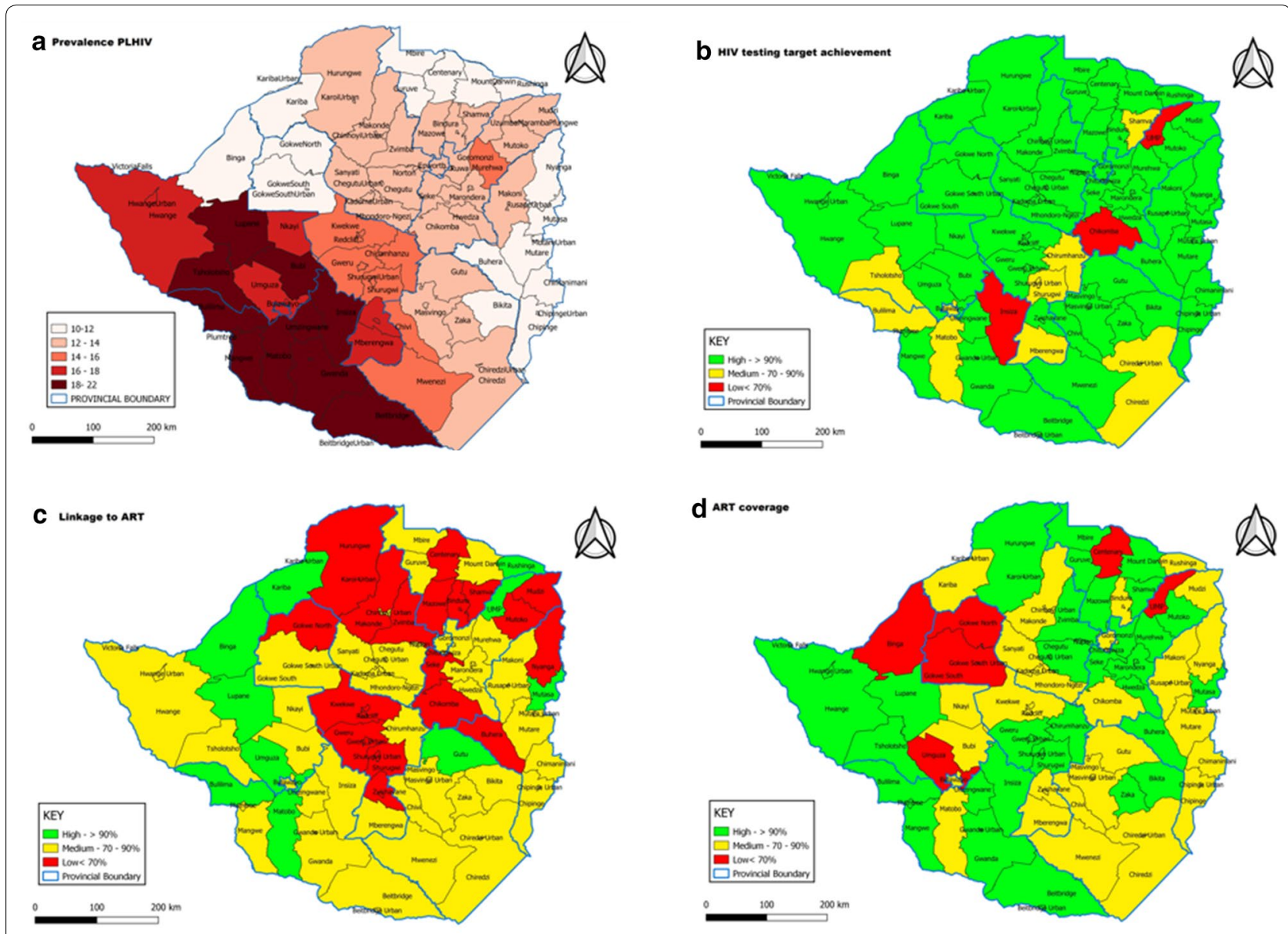

Created with Quantum GIS Version 3.1 an open source software.

Fig. 1 Maps showing; a HIV prevalence, $\mathbf{b}$ HIV testing target achievement, $\mathbf{c}$ linkage to ART, $\mathbf{d}$ ART coverage

\section{High testing target achievement and suboptimal linkage to ART}

Eighteen districts with suboptimal ART coverage that achieved their HIV testing target but with suboptimal linkage to ART should assess if strategies known to improve linkage to care and ART initiation are in place. These strategies include same-day ART initiation, community (home-based) ART initiation, decentralisation of ART services to the primary health care level and integration of HIV care in other health care services [13-17]. Linkage to ART should be regularly assessed at the health facility level. Those who are diagnosed with HIV but have not been started on ART should be tracked. Consent for tracking should be incorporated into the testing strategy [18]. Patients diagnosed at higher-level referral health facilities should be initiated on ART before down referral to lower-level health facilities for follow up, with tracking of arrival after referral [19]. Some districts may have specific challenges. Poor linkage to ART around Kwekwe and the surrounding districts might be explained by the presence of illegal artisanal miners in the region. Illegal artisanal miners are highly mobile, and strategies to link and retain these highly mobile populations should be identified [20, 21]. Also, in districts bordering Zambia and Mozambique (Centenary, Mudzi and Nyanga), the poor linkage may be due to patients crossing the border as a result of the economic challenges in Zimbabwe. The Southern African Development Community (SADC) HIV and AIDS Cross Border Initiative should be fully implemented to enable the provision of care and tracking of such patients [22-24].

\section{High testing target achievement and high linkage to ART}

Six districts with suboptimal ART coverage achieved their HIV testing targets and had high linkage to ART. In such a scenario, other indicators may assist in the formulation of a district-specific strategy. If the prevalence and HIV testing yield are lower than average, HIV testing may need to be delivered in a more targeted manner. Health facility-based strategies in combination 
Table 1 HIV cascade for 30 districts with suboptimal (<90\%) ART coverage in 2018, Zimbabwe

\begin{tabular}{|c|c|c|c|c|c|}
\hline District & ART Coverage (\%) & $\begin{array}{l}\text { HIV target testing } \\
\text { achievement }(\%)\end{array}$ & Linkage to ART (\%) & Yield (\%) & $\begin{array}{l}\text { Prevalence } \\
\text { (\%) }\end{array}$ \\
\hline \multicolumn{6}{|c|}{ Suboptimal HIV testing target achievement and suboptimal linkage to ART } \\
\hline Chikomba & 77 & 63 & 54 & 7 & 13 \\
\hline Mberengwa & 77 & 89 & 71 & 6 & 17 \\
\hline Chiredzi & 80 & 89 & 81 & 6 & 13 \\
\hline Bulawayo & 83 & 73 & 77 & 8 & 16 \\
\hline \multicolumn{6}{|c|}{ High HIV testing target achievement and suboptimal linkage to ART } \\
\hline Gokwe North & 39 & 125 & 63 & 4 & 10 \\
\hline Gokwe South & 44 & 129 & 71 & 4 & 12 \\
\hline Centenary & 61 & 119 & 55 & 6 & 12 \\
\hline Bubi & 70 & 131 & 83 & 4 & 22 \\
\hline Bindura & 75 & 140 & 29 & 15 & 14 \\
\hline Nyanga & 75 & 123 & 35 & 7 & 11 \\
\hline Zvishavane & 75 & 117 & 59 & 8 & 18 \\
\hline Harare & 78 & 110 & 75 & 7 & 13 \\
\hline Kadoma & 78 & 358 & 72 & 7 & 13 \\
\hline Nkayi & 78 & 179 & 86 & 3 & 17 \\
\hline Kwekwe & 79 & 115 & 67 & 8 & 14 \\
\hline Mudzi & 81 & 96 & 43 & 6 & 12 \\
\hline Makonde & 82 & 189 & 69 & 6 & 13 \\
\hline Mutare & 82 & 206 & 80 & 4 & 11 \\
\hline Chipinge & 85 & 123 & 81 & 5 & 11 \\
\hline Mwenezi & 86 & 122 & 76 & 7 & 15 \\
\hline Chimanimani & 88 & 155 & 74 & 4 & 11 \\
\hline Masvingo & 88 & 142 & 74 & 7 & 14 \\
\hline \multicolumn{6}{|c|}{ High HIV testing target achievement and high linkage to ART } \\
\hline Umguza & 50 & 94 & 96 & 5 & 18 \\
\hline Binga & 68 & 122 & 121 & 2 & 12 \\
\hline Rushinga & 75 & 137 & 101 & 2 & 11 \\
\hline Gutu & 77 & 132 & 100 & 3 & 13 \\
\hline Makoni & 87 & 151 & 90 & 4 & 12 \\
\hline Kariba & 89 & 184 & 100 & 5 & 12 \\
\hline \multicolumn{6}{|c|}{ Suboptimal HIV testing target achievement and high linkage to ART } \\
\hline UMP & 63 & 63 & 110 & 7 & 12 \\
\hline Matobo & 76 & 80 & 105 & 5 & 19 \\
\hline
\end{tabular}

with community testing in high-risk groups may be most efficient. Health facility-based strategies that have worked elsewhere include index case testing, targeting sexual partners and HIV-exposed infants and intensified provider-initiated testing and counselling (IPITC) [25-31]. Community testing should prioritise subgroups with a higher prevalence. Key populations and hotspots identified from a mapping exercise conducted in Zimbabwe may guide programming [32]. Social network testing, using peer educators, can be a useful tool to reach some of the key populations [30].

\section{Suboptimal HIV testing target achievement and high linkage} to ART

There were two districts with suboptimal ART coverage that had suboptimal HIV testing target achievement but with high linkage to ART. In both, the HIV prevalence and testing yield were higher than average. Hence, HIV testing strategies recommended for high prevalence settings, discussed above, should be considered.

In conclusion, there is substantial within-country variation in terms of HIV prevalence, HIV testing target achievement, HIV testing yield, linkage to ART and ART 
coverage. Hence, a "one size fits all" approach is unlikely to result in achieving the next UNAIDS 95-95-95 targets by the end of 2030. District-level mapping of uncovered needs and gaps along the HIV cascade of care is needed, particularly for districts with suboptimal ART coverage.

\section{Limitations}

Our study is among the first to assess the performance across the HIV care cascade at the sub-national level. To validate our findings, we compared data from a variety of sources. However, there are limitations due to the cross-sectional design of our study. Crossover of patients between prior or later years with 2018 may have occurred, for instance, when patients diagnosed in 2017 started ART in 2018, and those diagnosed in 2018 started ART in 2019. The district HIV testing targets were calculated by using the percentage of the number of PLHIV per district to distribute the national HIV testing target without considering the context and performance of each district cascade of care. The MoHCC have since started estimating district yearly HIV testing targets by taking into consideration the context and district-specific parameters. Moreover, district-level data on the third "90" from the UNAIDS 90-90-90 targets, i.e. viral suppression, was unavailable. Previous studies showed that the retention on ART was high, while access to viral load monitoring and viral load suppression remained suboptimal [33-35].

\section{Supplementary information}

Supplementary information accompanies this paper at https://doi. org/10.1186/s13104-020-05234-8.

Additional file 1: Figure S1. Yield per district among HIV tests performed in 2018 in Zimbabwe.

\begin{abstract}
Abbreviations
$\mathrm{Cl}$ : Confidence interval; MoHCC: Ministry of Health and Child Care; HIV: Human Immunodeficiency Virus; AIDS: Acquired Immunodeficiency Syndrome; ART: Antiretroviral therapy; PLHIV: People living with HIV; IPITC: Intensified Provider Initiated Testing and Counselling; UNAIDS: Joint United Nations Programme on HIV/AIDS.
\end{abstract}

\section{Acknowledgements}

The authors of the articles would like express gratitude and appreciation to Lindgren et al. (2019) from the Institute for Health Metrics and Evaluation, University of Washington, Seattle, WA, USA for the permission to use Zimbabwe data on HIV prevalence and number of PLHIV and the Ministry of Health and Child care for providing data on the number on ART per district by the end of 2018.

\section{Authors' contributions}

RM led the conceptualisation of the paper, data analysis and writing of the original draft paper. ZKC developed the maps. TD, LL, ZKC, VWD, JH and SR reviewed all sections of the manuscript. All authors contributed to interpreting the data and editing of the paper, and all approved the final version. All authors read and approved the final manuscript.

\section{Funding}

Richard Makurumidze receives a PhD scholarship grant from the Institute of Tropical Medicine, Antwerp, Belgium funded by the Belgian Development Cooperation (DGD). The funder had no role in the design of the study; collection, analysis, and interpretation of data and in the writing of the manuscript.

\section{Availability of data and materials}

Zimbabwe data on HIV prevalence and the number of PLHIV is publicly available at http://ghdx.healthdata.org/ihme-data/africa-hiv-prevalence-geospatial estimates-2000-2017. The data from the Ministry of Health and Child Care on the number on ART per district by the end of 2018 is not available in the public domain. Anyone interested in using the data for scientific purpose is free to request permission from the Director of the AIDS and TB Program, AIDS and TB Unit, Ministry of Health and Child Care, Government of Zimbabwe, 2nd Floor, Mukwati Building, Harare, Zimbabwe. Email: atp.director@ymail.com

\section{Ethics approval and consent to participate}

Not applicable.

\section{Consent for publication \\ Not applicable.}

\section{Competing interests}

The authors have no competing interests.

\section{Author details}

${ }^{1}$ College of Health Sciences, University of Zimbabwe, Harare, Zimbabwe. ${ }^{2}$ Institute of Tropical Medicine, Antwerp, Belgium. ${ }^{3}$ Research Foundation of Flanders, Brussels, Belgium. ${ }^{4}$ Gerontology, Faculty of Medicine \& Pharmacy, Free University of Brussels (VUB), Brussels, Belgium. ${ }^{5}$ Ministry of Health and Child Care, Geographic Information System Department, Harare, Zimbabwe.

Received: 31 January 2020 Accepted: 14 August 2020

Published online: 26 August 2020

References

1. Joint United Nations Programme on HIV/AIDS (UNAIDS). UNAIDS Data. 2019. https://www.unaids.org/en/resources/documents/2019/2019UNAIDS-data. Accessed 26 July 2020.

2. Joint United Nations Programme on HIV/AIDS (UNAIDS). 90-90-90-An ambitious treatment target to help end the AIDS epidemic. 2014. https ://www.unaids.org/sites/default/files/media_asset/90-90-90_en.pdf. Accessed 26 July 2020.

3. Ministry of Health and Child Care (MOHCC)-Zimbabwe. Zimbabwe Population-based HIV Impact Assessment (ZIMPHIA) 2015-2016: First Report. 2017. https://phia.icap.columbia.edu/countries/zimbabwe/; https :/phia.icap.columbia.edu/wp-content/uploads/2017/11/ZIMPHIA_First _Report_FINAL.pdf. Accessed 26 July 2020.

4. The United States President's Emergency Plan for AIDS Relief (PEPFAR). 2019 Annual Report to Congress. 2019. https://www.state.gov/wp-conte nt/uploads/2019/09/PEPFAR2019ARC.pdf. Accessed 26 July 2020.

5. Médecins Sans Frontières. Urgent boost and reality check needed for HIV and TB funding. 2019. https://www.msf.org/urgent-boost-and-reali ty-check-needed-hiv-and-tb-funding. Accessed 26 July 2020.

6. Dwyer-Lindgren L, Cork MA, Sligar A, Steuben KM, Wilson KF, Provost NR, Mayala BK, VanderHeide JD, Collison ML, Hall JB, et al. Mapping HIV prevalence in sub-Saharan Africa between 2000 and 2017. Nature. 2019;570(7760):189-93. https://doi.org/10.1038/s41586-019-1200-9.

7. Ministry of Health and Child Care (MOHCC)-Zimbabwe: National Programme ART Summary. 2018.

8. Ministry of Health and Child Care (MOHCC)-Zimbabwe. Extended Zimbabwe National AIDS Strategic Plan III (ZNASP III). 2020. http://nac.org.zW/ wp-content/uploads/2019/01/Extended-Zimbabwe-National-AIDS-Strat egic-Plan-3.pdf. Accessed 26 July 2020.

9. Ministry of Health and Child Care (MOHCC)-Zimbabwe: Zimbabwe National HIV Estimates 2015. Harare, Zimbabwe. 2015.

10. European Centre for Disease Prevention and Control (ECDC). Thematic report: Continuum of HIV care. Monitoring implementation of the Dublin 
Declaration on Partnership to Fight HIV/AIDS in Europe and Central Asia: 2017 progress report. Stockholm: ECDC. 2017. https://ecdc.europa.eu/ sites/portal/files/documents/Continuum-of-HIV-care-2017.pdf. Accessed 26 July 2020.

11. World Health Organization. Consolidated guidelines on the use of antiretroviral drugs for treating and preventing HIV infection: recommendations for a public health approach. Geneva, Switzerland. 2016. https:// apps.who.int/iris/bitstream/handle/10665/208825/9789241549684_eng. pdf? sequence $=1$. Accessed 26 July 2020.

12. World Health Organization. Guidelines on HIV self-testing and partner notification-Supplement to consolidated guidelines on HIV testing services. 2016. https://apps.who.int/iris/bitstream/handle/10665/25165 5/9789241549868-eng.pdf?sequence=1. Accessed 26 July 2020.

13. Labhardt ND, Ringera I, Lejone TI, Klimkait T, Muhairwe J, Amstutz A, Glass TR. Effect of Offering Same-Day ART vs Usual Health Facility Referral During Home-Based HIV Testing on Linkage to Care and Viral Suppression Among Adults With HIV in Lesotho: The CASCADE Randomized Clinical Trial. JAMA. 2018. https://doi.org/10.1001/jama.2018.1818.

14. Govindasamy D, Ford N, Kranzer K. Risk factors, barriers and facilitators for linkage to antiretroviral therapy care: a systematic review. AIDS. 2012;26(16):2059-67. https://doi.org/10.1097/QAD.0b013e3283578b9b.

15. Decroo T, Rasschaert F, Telfer B, Remartinez D, Laga M, Ford N. Community-based antiretroviral therapy programs can overcome barriers to retention of patients and decongest health services in sub-Saharan Africa: a systematic review. Int Health. 2013;5(3):169-79. https://doi. org/10.1093/inthealth/iht016.

16. MacPherson P, Lalloo DG, Webb EL, Maheswaran H, Choko AT, Makombe SD, Butterworth AE, van Oosterhout JJ, Desmond N, Thindwa D, et al. Effect of optional home initiation of HIV care following HIV self-testing on antiretroviral therapy initiation among adults in Malawi: a randomized clinical trial. JAMA. 2014;312(4):372-9. https://doi.org/10.1001/ jama.2014.6493.

17. Giordano TP. Strategies for linkage to and engagement with care: focus on intervention. Top Antivir Med. 2018;26(2):62-5.

18. Tweya H, Oboho IK, Gugsa ST, Phiri S, Rambiki E, Banda R, Mwafilaso J, Munthali C, Gupta S, Bateganya M, Maida A. Loss to follow-up before and after initiation of antiretroviral therapy in HIV facilities in Lilongwe, Malawi. PLoS ONE. 2018. https://doi.org/10.1371/journal.pone.0188488.

19. Decroo T, Panunzi I, das Dores C, Maldonado F, Biot M, Ford N, Chu K. Lessons learned during down referral of antiretroviral treatment in Tete, Mozambique. J Int AIDS Soc. 2009;12:6. https://doi. org/10.1186/1758-2652-12-6.

20. Joint United Nations Programme on HIV/AIDS (UNAIDS), International Organization for Migration (IOM). Mobile Populations and HIV/AIDS in the Southern African Region. 2003. https://publications.iom.int/system/files/ pdf/hiv_southafrica1.pdf. Accessed 26 July 2020.

21. Taylor BS, Garduno LS, Reyes EV, Valino R, Rojas R, Donastorg Y, Brudney K, Hirsch J. HIV care for geographically mobile populations. Mt Sinai J Med. 2011;78(3):342-51. https://doi.org/10.1002/msj.20255.

22. Vearey J. Moving forward: why responding to migration, mobility and HIV in South(ern) Africa is a public health priority. J Int AIDS Soc. 2018. https:// doi.org/10.1002/jia2.25137.

23. Southern African Development Community (SADC). Statement of SADC Ministers of Health and Ministers Responsible for HIV and AIDS Meet in Namibia 8th November 2018. 2018. https://www.sadc.int/files /3315/4169/8409/Media_Statement_-_Joint_Meeting_of_SADC_Minis ters_of_Health_and_those_responsible_for_HIV_and_AIDS_.pdf. Accessed 26 July 2020.

24. Southern African Development Community (SADC). SADC HIV and AIDS Cross Border Initiative. 2013. https://www.comminit.com/africa/content/ sadc-hiv-and-aids-cross-border-initiative. Accessed 26 July 2020.
25. Lasry A, Medley A, Behel S, Mujawar MI, Cain M, Diekman ST, Rurangirwa J, Valverde E, Nelson R, Agolory S, et al. Scaling Up Testing for Human Immunodeficiency Virus Infection Among Contacts of Index Patients-20 Countries, 2016-2018. MMWR. 2019;68:21:474-7. doi:http://dx.doi. org/10.15585/mmwr.mm6821a2; https://www.cdc.gov/mmwr/volum es/68/wr/mm6821a2.htm.

26. Jubilee M, Park FJ, Chipango K, Pule K, Machinda A, Taruberekera N. HIV index testing to improve HIV positivity rate and linkage to care and treatment of sexual partners, adolescents and children of PLHIV in Lesotho. PLoS ONE. 2019;14(3):e0212762. https://doi.org/10.1371/journ al.pone. 0212762 .

27. Ahmed S, Sabelli RA, Simon K, Rosenberg NE, Kavuta E, Harawa M, Dick S, Linzie F, Kazembe PN, Kim MH. Index case finding facilitates identification and linkage to care of children and young persons living with HIV/AIDS in Malawi. Trop Med Int Health. 2017;22(8):1021-9. https://doi.org/10.1111/ tmi.12900.

28. Mahachi N, Muchedzi A, Tafuma TA, Mawora P, Kariuki L, Semo BW, Bateganya MH, Nyagura T, Ncube G, Merrigan MB, et al. Sustained high HIV case-finding through index testing and partner notification services: experiences from three provinces in Zimbabwe. J Int AIDS Soc. 2019. https://doi.org/10.1002/jia2.25321.

29. Sharma M, Smith JA, Farquhar C, Ying R, Cherutich P, Golden M, Wamuti B, Bukusi D, Spiegel H, Barnabas RV. Assisted partner notification services are cost-effective for decreasing HIV burden in western Kenya. AIDS. 2018;32(2):233-41. https://doi.org/10.1097/QAD.00000000000001697.

30. ICAP; Columbia University-Mailman School of Public Health. ICAP Approach to Strategic HIV Testing. 2017. https://icap.columbia.edu/wpcontent/uploads/ICAP_Approach_to_Strategic_HIV_Testing_20Julyl17. pdf. Accessed 26 July 2020.

31. Kayigamba FR, Van Santen D, Bakker MI, Lammers J, Mugisha V, Bagiruwigize E, DeNaeyer L, Asiimwe A, Van Der Loeff MF. Does provider-initiated HIV testing and counselling lead to higher HIV testing rate and HIV case finding in Rwandan clinics? BMC Infect Dis. 2016;16:26. https://doi. org/10.1186/s12879-016-1355-z.

32. Zimbabwe National AIDS Council, Zimbabwe Ministry of Health and Child Welfare, UNAIDS, World Food Programme VAM Food Security Analysis, CDC. Smart investment to end HIV/AIDS in Zimbabwe based on hotspot analysis. 2015. https://procurement-notices.undp.org/view_file. cfm?doc_id=114244. Accessed 26 July 2020.

33. Makurumidze R, Mutasa-Apollo T, Decroo T, Choto RC, Takarinda KC, Dzangare J, Lynen L, Van Damme W, Hakim J, Magure T, et al. Retention and predictors of attrition among patients who started antiretroviral therapy in Zimbabwe's national antiretroviral therapy programme between 2012 and 2015. PLoS ONE. 2012. https://doi.org/10.1371/journ al.pone.0222309.

34. The United States President's Emergency Plan for AIDS Relief (PEPFAR). Zimbabwe Country Operational Plan (COP/ROP) 2018 Revised Strategic Direction Summary. 2018. https://www.pepfar.gov/documents/organizati on/285847.pdf. Accessed 26 July 2020.

35. Ministry of Health and Child Care (MOHCC) - Zimbabwe. Zimbabwe Population-based HIV Impact Assessment (ZIMPHIA) 2015-2016: Final Report. 2019. https://phia.icap.columbia.edu/countries/zimbabwe/; https ://phia.icap.columbia.edu/wp-content/uploads/2019/08/ZIMPHIA-Final -Report_integrated_Web-1.pdf. Accessed 26 July 2020.

\section{Publisher's Note}

Springer Nature remains neutral with regard to jurisdictional claims in published maps and institutional affiliations. 